\title{
Human Ascariasis Increases the Allergic Response and Allergic Symptoms
}

\author{
Luis Caraballo $^{1,2}$ - Nathalie Acevedo ${ }^{1,2} \cdot$ Emiro Buendía $^{1}$
}

Published online: 30 September 2015

(C) Springer International Publishing AG 2015

\begin{abstract}
Ascariasis is still very prevalent; one billion people are infected all around the world. In rural areas, severe ascariasis impairs the immune responses to natural infections and vaccination programs. However, in urbanized areas, improved hygiene conditions and periodic anthelmintic treatments have led to light forms of ascariasis, where parasite-induced immunosuppressive effects are surpassed by the immunostimulating effects of the infection. During the last years, the clinical impact of this type of ascariasis on allergic diseases, especially asthma, has been well documented, and it is currently accepted that this relationship should be considered when analyzing allergy prevalence in tropical and temperate countries. This review focuses on the emerging evidence that supports the stimulatory effects of ascariasis on the allergic responses and its clinical importance. Advances on the role of type 2 innate lymphoid cells (ILC2) in helminth immunity and allergy pathogenesis as well as new genetic findings supporting the links between helminthiases and allergy are discussed. We show that ascariasis, beyond its known effects on human health, is able to modify the natural history of asthma, increasing Th2
\end{abstract}

This article is part of the Topical Collection on Topics Exploring Loa-Loa, Onchocerciasis, Hookworm, Ascaris, Trichuris

Luis Caraballo

lcaraballog@unicartagena.edu.co

Nathalie Acevedo

nathalie.acevedo@fundemeb.org

Emiro Buendía

ebuendiad@unicartagena.edu.co

1 Institute for Immunological Research, University of Cartagena, Cartagena, Colombia

2 Foundation for the Development of medical and biological sciences (Fundemeb), Cartagena, Colombia responses and IgE synthesis to cross-reactive and speciesspecific mite allergens, being a risk factor for asthma and asthma severity.

Keywords Ascariasis · IgE · Allergy $\cdot$ House dust mites · Helminths $\cdot$ Asthma $\cdot$ Genetics $\cdot$ ILC2

\section{Introduction}

The most common human helminthiases are caused by soiltransmitted nematodes (Ascaris lumbricoides, Trichuris trichiura, Ancylostoma duodenalis, Necator americanus, Strongyloides stercoralis), filarial nematodes (Wuchereria bancrofti, Brugia malayi, Onchocerca volvulus), and platyhelminth flukes (Schistosoma haematobium, Schistosoma mansoni, Schistosoma japonicum). The immune response elicited by these infections differs depending on the type of parasite, lifecycle, host age, burden of co-infections (polyparasitism), and parasite loads. However, all share as hallmarks an increase in circulating IgE levels, peripheral and intestinal eosinophilia, and the activation of genes and cytokine networks related to type 2 immunity and immunomodulation $[1,2]$.

A. lumbricoides induces a Th2-biased immune response, similar to that observed in the allergic response but associated with parasite-induced immunomodulation, a condition that could be evolutionary related with the helminths ability of parasitic life. Therefore, ascariasis can influence allergic diseases by either stimulating or suppressing the allergic response, probably depending on the severity of the infection, which in turn is determined by host genetic susceptibility and the degree of exposure. A number of epidemiologic surveys suggest that nowadays, severe, chronic infections, with heavy worm loads and polyparasitism are present in rural areas of the 
tropics, while intermittent and low-intensity infections occur mainly in urbanized areas, being A. lumbricoides and T. trichiura the most common parasites. As a consequence, risk or protector factors for allergy in the tropics include helminthiases. During the last few years, it has become clear that ascariasis may influence several aspects of allergy, such as prevalence, diagnosis, severity, and prevention. Studying the relationships between ascariasis and allergy could help to understand fundamental questions about type 2 immunity, allergy mechanisms, and clinical phenotypes. Since an inverse prevalence rates between helminthiases and allergy has been found, future research could provide insights on the origin of the high prevalence of allergy in urbanized zones of the tropics. In this review, we analyze the evidence supporting that, in the current relationship between ascariasis and allergy, the most important effect of ascariasis is increasing allergic symptoms.

\section{The Increasing Trends of Allergy}

Allergic diseases (allergy) result from the interaction between genetic predisposition and environmental factors. Among genetic predisposing factors, atopy (the tendency to react with IgE antibodies against innocuous antigens, a condition also known as "IgE sensitization" or merely "sensitization") is one of the most studied. However, other heritable components are required to conform to the clinically evident phenotype. The best known environmental factors are the allergens, including molds, pollens, house dust mites (HDM), foods, pets, etc. People in the tropics are permanently exposed to HDM allergens, which are the main cause of asthma in this zone. However, other factors and conditions, such as pollution, diet, biodiversity, microbiome composition, and infections (viral and parasitic) can modify the natural history of allergy. During the few last years, the epigenetic modifications induced by some of these environmental signals have been revealed. Asthma, rhinitis, and atopic dermatitis are the prototypes of allergic diseases. In addition, there are a number of allergic reactions including those to foods, stinging insects, and drugs that could induce anaphylaxis, a severe, lifethreatening condition. The prevalence of allergic diseases is increasing worldwide including underdeveloped countries of the tropics [3]. Among the numerous possible factors underlying this trend [4], the progressive lack of the immunomodulatory effect of helminthiases is salient. These infections have already been controlled in most industrialized countries and are under control in urbanized zones of the tropics (Fig. 1). Then, the relationships between helminthiases and allergy extend beyond the basic and clinical sciences to cover important worldwide epidemiological trends. These interesting links are partially explained by the common aspects of helminth immunity mechanisms and the allergic response. A number of

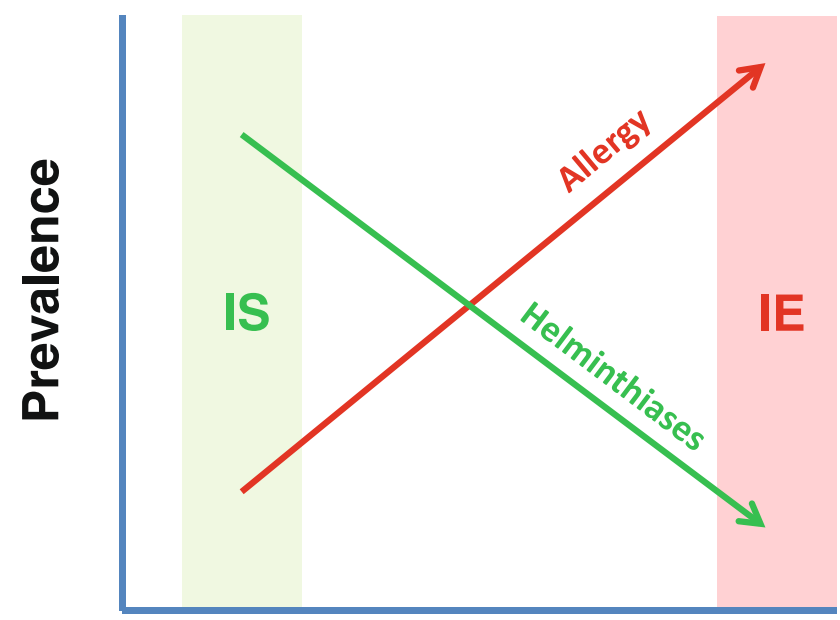

\section{Urbanization}

Fig. 1 Hypothetical presentation of the effect of helminthiases control on the prevalence of allergic diseases. Immunosuppression (IS) reaches its maximum when helminthiases are prevalent and the burden of infections is very high; inducing severe disease. In this setting, the prevalence of allergic symptoms is low. Immunostimulation (IE) is higher when the prevalence of helminthiases is lower, allowing intermittent and mild infections that increase allergic symptoms. The hypothesis assumes that the changes operate on a population genetically predisposed to allergy

recent reports on basic immunoparasitology have provided a better understanding of the immune responses to helminth infections (reviewed in [2]). Here, we present just a brief discussion of the role of innate lymphoid cells 2 (ILC2) on helminth immunity and allergy.

\section{The Immune Responses to Helminths and Allergens: Emerging Roles for Innate Lymphoid Cells 2}

Immunity to Ascaris involves antibodies and cellular mechanisms of the innate and adaptive responses. However, sterile immunity is not common and reinfection occurs frequently. After ingesting an embryonated infective egg, Ascaris lifecycle in the human host comprises larval penetration through the gut epithelia, migration through tissues, and adult settlement in the gut. The migration process causes tissue damage and antigen exposure to the immune system. Ascaris infection induces increased expression of the cytokines IL-4, IL-5, IL-9, IL-10, and IL-13; synthesis of specific antibodies to its antigens/allergens (including IgE); high titers of polyclonal IgE; eosinophilia; and activation of mast cells and basophils. This immune reaction is collectively known as Th2-type immunity and is similar to that observed in allergic inflammation. In the early stages of infection, ILC2 play an important role, whereas M2 macrophages and lymphocytes participate in later stages. However, together with this Th2skewed immune profile, Ascaris induces immunosuppressive responses including the expansion of regulatory $\mathrm{T}$ and $\mathrm{B}$ cells 
and production of suppressive cytokines (IL-10/TGF- $\beta$ ). After repeated exposure to the parasite, several effector mechanisms confer adaptive immunity and contribute to destroy the larvae during early stages of their migration (the so called "hepatic barrier"), or to expel the adult worms from the intestine. Ascaris induced high total IgE levels but most of these antibodies are not specific [5], resulting from a polyclonal stimulation of B cells [6]. This irrelevant IgE binds to its receptors on mast cells and eosinophils precluding their degranulation, and reducing the effector response against larvae [7].

The discovery of the cells currently known as ILC2 emerged from experimental nematode infections [8-10]. After their first descriptions in 2010, other reports have supported the role of ILC2 in immunity to helminths. Yasuda et al. showed that during infection by Schistosoma venezuelensis, lung epithelial cells produce IL-33 and induce proliferation of a type of ILC2. Their effects were independent of adaptive immunity but dependent on the IL-33 produced by the lung epithelium [11]. Indeed, the number of ILC2 was greater in the resistant mice strain BALB/c infected with Heligmosomoides polygyrus when compared with the susceptible C57BL/6 strain, thus supporting their role in antihelminth immunity [12]. ILC2 cells also have the capacity to proliferate in response to helminth carbohydrate chitin [13]. Moreover, IL-33 ${ }^{-/}$mice did not develop eosinophilia and goblet cell hyperplasia after intranasal administration of chitin [11]. Interestingly, some helminth infections suppress immune response by blocking the production of IL-25 and IL-33. Zaiss et al. found that $H$. polygyrus bakeri induces the production of IL-1 $\beta$ by epithelial cells in vivo and in vitro, blocking the production of IL-25, IL-33, and the proliferation of ILC2, allowing infection chronicity [14].

ILC2 control eosinophil homeostasis in helminth infection and macrophage differentiation to M2 phenotype $[9,10]$, possibly because the IL- 5 and IL-13 produced by these cells induce epithelial eotaxins and adhesins that promote eosinophil trafficking into the lung and other tissues [15, 16]. ILC2, through MHCII, collaborate with $\mathrm{T}$ lymphocytes that produce IL-2 that induces ILC2 proliferation and increased immunity [17]. Recently, these properties have also been observed in a mice model of asthma where ILC2 significantly increased the lung Th2 inflammatory responses to chronically administered ovalbumin [18].

ILC2 are involved in granuloma formation by Schistosoma eggs in the liver $[19,20]$. In contrast, they produce amphiregulin that can repair tissue damage induced by influenza virus infection [21]. This cytokine seem important for controlling helminth infection because amphiregulindeficient mice have more parasite burden at day 14 post infection with Trichuris muris when compared with the control wild type [22]. Another important ILC2-related cytokine is IL-9. Turner et al. showed that IL-9 receptor-deficient mice infected with Nippostrongylus brasiliensis have less ILC2 (Lin ${ }^{-}$Th1 1.2 ${ }^{+}$), IL-13, IL-5, and amphiregulin and more egg count and tissue damage during parasite migration [23].

In humans, Boyd et al. found increased IL-13 producing ILC2 in peripheral blood of adult patients with filarial infection. In this study, these cells expressed GATA3, similar to had been previously shown in mice [24]. In contrast, Nausch et al. found diminished ILC2 in peripheral blood of $S$. haematobium infected children [25•]. Since the immune responses to helminths and the allergic response have some similarities, the findings about ILC2 on type 2 immunity and helminth infection resistance have led to the study of their role in the allergic reaction [26]. A number of publications have shown that, as happens during helminth infection, these cells react early producing IL-13 and IL-5 during sensitization with various allergen extracts [27•] and recombinants allergens [28, 29] with the same dependence on IL-25 and IL-33 epithelial cytokines [28]. ILC2 are involved in the severity of allergy in an independent way or associated to $\mathrm{T}$ lymphocytes activation $[18,27 \cdot]$. Moreover, it has been shown that asthmatic individuals have more ILC2 $\left(\mathrm{Lin}^{-} \mathrm{CD} 127^{+} \mathrm{CRTH} 2^{+}\right)$in peripheral blood than patients with rhinitis and healthy individuals. In vitro, these cells produced higher quantities of IL-5 and IL-13 when cultured with IL-25 and IL-33 plus IL-2 [30]. It can be speculated that in the tropics, allergic individuals with an ILC2-hyperactive phenotype and concomitant helminth infection might have a boosted allergic response and more severe symptoms.

\section{Immunogenetics of the IgE Responses to Ascaris and Allergens}

Since the immune response to helminthiases shares several mechanisms with the allergic reaction, it is expected that they also have common genetic basis. In fact, several variants have been found associated with both helminth infections and allergy. Moreover, most of researchers in the field think that allergy is a collateral consequence of a protective response evolutionary modeled by helminth infections. However, most of the genes and polymorphisms associated with the IgE response to allergens and allergic diseases have not been related to helminth resistance. This suggests that IgE responses to allergens probably have their own evolutionary roots. This topic has become more complicated as it is realized that the number of the so-called immune response genes is greater than previously suspected. In this section, we discuss the genetic factors influencing the antibody response to helminths with emphasis on Ascaris and the scenarios in which they could contribute to the IgE sensitization to non-parasitic allergens.

Several facts suggest that there is an important genetic influence defining the susceptibility to helminth infections. It is 
typical that worm loads are over-dispersed in the infected communities with $20 \%$ of the individuals harboring $80 \%$ of the parasites [31]. Individual predisposition to get infected by heavy or light worm loads is maintained in treatmentreinfection studies [32], and aggregates in families [33, 34]. Epidemiological studies revealed than in addition to exposure and household determinants, genetic factors account for an important proportion of the variation in worm loads [35-38].

Genetic factors have been also found to influence the levels of protective antibodies against helminths, as shown for the IgG levels to larval and adult worm antigens in humans infected by $W$. bancrofti [36]. The heritability of circulating antibody levels against helminths (particularly $\operatorname{IgG}_{1}$ and $\mathrm{IgG}_{2}$ ) ranges between 70 and $80 \%$ depending upon time and isotype [39], and gene expression analyses have found that many genes differentially expressed between resistant and susceptible animals are indeed implicated in antibody synthesis [40]. A. lumbricoides is very allergenic and, as explained earlier, induces in the host a type- 2 skewed immune profile with several features that resemble the allergic response to non-parasitic allergens including the synthesis of specific IgE [41]. The role of this isotype in the resistance to Ascaris is controversial, but some studies have shown that worm loads and the proportion of re-infected children after treatment is significantly lower in individuals with the highest levels of anti-Ascaris IgE antibodies [42]. In endemic populations, most of the infected individuals produce specific IgE to Ascaris without developing allergic symptoms, suggesting that the regulation of the antibody response to helminths is polygenic, and genetic loci influencing the strength and specificity of the IgE response to helminths do not necessarily confer susceptibility to allergic asthma or IgE sensitization.

Nevertheless and considering the overlap in biological pathways implicated in the immune responses to helminths and allergens, it has been hypothesized that some genetic variants influencing the IgE response to helminths may also predispose to develop IgE sensitization with non-parasitic allergens [43] or even predispose to allergic diseases [44, 45]. Although the empirical evidence is limited, it can be noted that (i) the major histocompatibility complex (MHC) participate in determining susceptibility to helminthic infections [46]; (ii) some genetic variants are associated to both, susceptibility to helminthic infections and allergic sensitization, as shown for the genes encoding for interleukin 13 (IL13), the signal transducer and activator of transcription 6 (STAT6), and chitotriosidase; and (iii) other genetic loci regulate the antibody response to helminths without predisposing to allergy.

Studies in humans and other mammals support the role of genetic factors in the predisposition to Ascaris [37, 47] but few genes have been identified so far [43, 48-51, 52•]. A summary of genes and genomic regions associated with the susceptibility to human ascariasis is presented in Table 1.

\section{Common Genes for Ascaris Response and Allergic Phenotypes}

The enhanced resistance to parasitic worms through genetic variation has been observed in $\mathrm{Th} 2$ immune signaling genes and some also contribute to allergic susceptibility. Peisong et al. found an association between a common genetic variant of the 3'-UTR regulatory elements of STAT6 and Ascaris egg counts in China [49]. In addition, a cross-population comparison between haplotypes in China and United Kingdom revealed a negative correlation between worm burden and expected risk of asthma [43]. The 5q31 locus is another example of a common locus for the susceptibility to helminthic infection and allergic diseases. It contains genetic variants in the IL13 gene associated with the worm burden of Ascaris in a Chinese population.

Table 1 A summary of genes and genomic regions associated with the susceptibility to human ascariasis

\begin{tabular}{|c|c|c|c|c|c|}
\hline Gene & Locus & Genetic variant & Effect & Population & Ref. \\
\hline IL10 & $1 q 31-q 32$ & rs3024492 & $\begin{array}{l}\text { Allele C of rs } 3024498 \text { was negatively associated } \\
\text { with helminth infection }\end{array}$ & Brazil & {$[52]$} \\
\hline IL13 & $5 q 31$ & $-1055 \mathrm{C}>\mathrm{T}$ & $\begin{array}{l}\text { In combination with a common variant in the } 3 \text { 'region } \\
\text { of STAT6 contribute to diminish Ascaris burden }\end{array}$ & China & [49] \\
\hline \multirow[t]{2}{*}{ STAT6 } & $12 q 13$ & $\begin{array}{l}\text { Microsatellite in exon } \\
15^{\prime} \text { UTR/3'UTR haplotypes }\end{array}$ & $\begin{array}{l}\text { Carriers of the short allele in the microsatellite in } \\
\text { combination with SNPs haplotypes have lower } \\
\text { levels of Ascaris infection }\end{array}$ & China & [49] \\
\hline & & 3'UTR SNP 4219 G/A & $\begin{array}{l}\text { Homozygotes GG have the lowest egg counts and } \\
\text { protected to carry more than } 960 \text { eggs per gram of feces }\end{array}$ & China & [49] \\
\hline- & $13 q 33-34$ & D13S1265 D13S285 & $\begin{array}{l}\text { linkage with egg counts of } A \text {. lumbricoides in stool } \\
\text { and total IgE levels. Quantitative trait locus for } \\
\text { Ascaris burden }\end{array}$ & Nepal & {$[48,50]$} \\
\hline TNFSF13B & $13 \mathrm{q} 33$ & $\mathrm{G} 3980>\mathrm{C}$ & $\begin{array}{l}\text { GG homozygotes have higher levels of IgG to Ascaris. } \\
\text { In asthmatics; carriers of the G allele have higher } \\
\text { levels of IgE against the resistance marker ABA-1 }\end{array}$ & Colombia & {$[51]$} \\
\hline
\end{tabular}


Genes encoding for human chitinases have been also identified as a potential link between ancestral responses to invertebrates and the susceptibility to allergic phenotypes. In humans, chitinases promote Th2 responses. The acidic mammalian chitinase (AMCase) is induced in epithelial cells and macrophages by an IL-13-mediated pathway and is expressed at high quantities in human asthma [53]. Genetic polymorphisms in chitinase genes have been associated with asthma [54], and asthmatic children exhibited increased chitinase activity and increased YKL-40 levels in BALF [55]. Genetic variants in the gene encoding chitotriosidase (CHITI) have not only been associated with the response to filarial infection but also with asthma [56, 57].

Experiments using different strains of mice and rats demonstrated the MHC-restriction in the recognition of excretory-secretory products of Ascaris and the genetic control of the antibody response to its antigens [58-62]; however, the relationship between human MHC alleles and the specificity of the antibody response to $A$. lumbricoides is unknown.

\section{The Ascaris Susceptibility Locus in Chromosome 13q33}

Linkage studies identified a quantitative trait locus (QTL) accounting for the variability in Ascaris egg counts and total IgE levels in chromosome 13q33-34 [48]. A second linkage-based genome scan including 1258 members of a single pedigree identified three potential QTLs influencing susceptibility to A. lumbricoides with genome-wide significance, localized on chromosomes 8, 11, and 13 [50]. Of these regions, the $13 \mathrm{q} 33$ locus is of great interest because it contains the gene TNFSF13B encoding for the cytokine B cell activating factor (BAFF). We studied the role of common variants in the $13 \mathrm{q} 33$ locus on the $\operatorname{IgE}$ and IgG levels against Ascaris and the putative resistance marker ABA-1, and identified a region of $125 \mathrm{~kb}$ harboring two polymorphisms significantly associated with antibody levels against Ascaris [51]. The effect of this variant was observed in both, non-asthmatic and asthmatics suggesting that participates in pathways implicated in antibody synthesis under physiological conditions and is not directly associated with allergic sensitization and/or asthma. At this point, it is unclear if the association in LIG4 is functionally related with this gene or resulted of the linkage disequilibrium with other variants. Furthermore, the polymorphism rs10508198 (3980G $>$ C) in the TNFSF13B gene was associated to the specific IgG levels to Ascaris. The carriers of the wild-type genotype GG have the highest levels of specific $\operatorname{IgG}$ to Ascaris in both non-asthmatics and asthmatics, suggesting that TNFSF 13B may regulate the strength of the antibody levels against Ascaris. There was no association between markers in the $13 \mathrm{q} 33$ locus and the IgE levels to HDM s or the presence of asthma [51].

\section{The Complex Relationship Between Ascariasis and Allergy}

The first observations about ascariasis and allergy were around the presence or increase of allergy symptoms (mainly asthma and urticaria) associated with Ascaris infection [63, 64]. The next link was the finding that both, helminthiases and allergy, were associated with high levels of total IgE, which was further extended to other features of the immune responses to both processes [65-68]. This has been followed by epidemiological reports that, using several approaches, have shown that ascariasis is a risk factor for asthma [69-77]. However, although there is abundant scientific literature supporting the boosting effect of ascariasis on allergic responses [5, 63-67, 69-76, 78-92, 93•, 94•, 95, 96•, 97, 98] (Table 2), a number of questions remain regarding the mechanisms for inducing an increased allergic response and asthma symptoms in a condition naturally accompanied by immunosuppression (reviewed in $[99,100]$ ). The answers could be related to several factors such as the permanent co-exposure to both HDM and A. lumbricoides that induces an enhanced Th2 response, cross reactivity between Ascaris and HDM allergens, nonspecific boosting of the allergic responses by Ascaris components, and intermittent Ascaris infections and deworming campaigns. Our recent work has focused on some of these aspects, as follows.

\section{Exposure to HDM Allergens and Ascaris Infections Is Permanent in the Tropics}

One of the particularities influencing allergy in the tropics is the permanent exposure to HDM and helminth infections. The mean annual temperature and humidity of $28{ }^{\circ} \mathrm{C}$ and $85 \%$, respectively, favor mites' growth and the lifecycle of Ascaris. Children born and raised in underdeveloped tropical countries are sensitized to both mite and Ascaris allergens at an early age [92]. For some sources such as Blomia tropicalis, the adult level of sensitization is reached at the age of 3 years [92, 101]. Therefore, an interesting characteristic of allergy in the tropics is the high rate of sensitization to HDM allergens and the high strength of that specific IgE response. This phenotype has been described in Asian as well as Latin American tropical countries and could be the result of a selective effect of perennial exposure on the population genetically susceptible to atopy and hyperreactivity to Ascaris infection. This population will be sensitized by very small amounts of allergens, an often forgotten feature of atopy, but the strength of the IgE response could increase with perennial exposure, as occurs in the tropics. 
Table 2 List of experimental and epidemiological data supporting that ascariasis enhances IgE responses to environmental allergens and allergic symptoms

\begin{tabular}{ll}
\hline Finding & References \\
\hline Natural infection is associated with a polarized Th2 cytokine response and high levels of total and anti-Ascaris $\operatorname{IgE}$ & {$[5,65,73,78-85]$} \\
In some individuals, natural infection induces IgE-mediated allergic respiratory and cutaneous symptoms & {$[63,86,87]$} \\
In experimental human and animal models, bronchial challenges with Ascaris extract induce asthma symptoms & {$[64,66,67]$} \\
Experimental ascariasis in animals enhances IgE response to bystander antigens & {$[88-91]$} \\
Human ascariasis enhances IgE response to mite species-specific allergens & {$[92,93 \cdot, 94 \cdot]$} \\
Several epidemiological surveys have found that ascariasis is a risk factor for asthma and atopy & {$[69-75,93 \cdot, 94 \cdot, 95,96 \bullet]$} \\
IgE responses to Ascaris allergens is more frequent and stronger in mite-sensitized asthmatic patients & {$[76,81,97,98]$}
\end{tabular}

\section{Cross Reactivity Between Mites and Ascaris Components Has Clinical Significance}

Since ascariasis and HDM exposure are very common in the tropics, it is possible that IgE responses to both sources can be increased by cross-reacting epitopes. We first described that there is high cross reactivity between HDM and Ascaris, mostly determined by tropomyosins. In this work, we also confirmed that ABA-1 (Asc s 1), a polyprotein of Ascaris spp., does not have cross reactivity with mite allergens. In other words, that ABA-1 is useful for diagnosing ascariasis in HDM-sensitized subjects $[99,102]$. These investigations were followed by the isolation and immunological characterization of Ascaris tropomyosin (Asc 13 ) as the main crossreactive allergen of this nematode [103] and the finding that Ascaris glutathione transferase (GST) apparently has less allergenic activity than tropomyosin [104, 105]. Having isolated and produced them as recombinant proteins, we were able to evaluate the role of these and other allergens as risk factors for asthma and asthma severity. In a nationwide study that included 356 asthmatics and 435 controls, we found that sensitization to Ascaris and mite tropomyosins were risk factors for asthma in the Colombian population [93•]. This work confirmed that sensitization to both Ascaris and Dermatophagoides pteronyssinus extracts were important risk factors for asthma and, in addition, for the first time showed that a molecular component of Ascaris is strongly associated with asthma. Since there is strong cross reactivity among mites and Ascaris tropomyosins, it is possible that primary sensitization (being from mites or Ascaris components) had been boosted by perennial exposure to the other cross-reacting source. In other asthma cohort from the tropics, we also found that not only sensitization to Ascaris extract but also to mite and Ascaris components were associated with symptoms of asthma severity, mainly severe dyspnea and more than four visits to the emergency room during last year [94•]. These studies support the role of Ascaris sensitization to speciesspecific and cross-reactive allergens in asthma pathogenesis, and, together with other recent reports $[95,96 \bullet]$, show that ascariasis is an important factor modifying the IgE responses and the natural history of asthma in the tropics.

\section{Ascariasis Induces Nonspecific Boosting of IgE Responses to Mite Allergens}

As has been observed in experimental models, ascariasis can boost the IgE/Th2 responses to bystander antigens [88-90]. Since it might help to explain the increasing allergy effects of Ascaris, we have explored this aspect in human ascariasis. Evaluating the evolution of the immune responses in children of the FRAAT birth cohort [106], we found that Ascaris-sensitized children had stronger IgE to the mite $B$. tropicalis. To rule out the confounding effect of cross reactivity, we used species-specific components and found that those reacting with IgE to ABA-1 (a marker of nematode infection) had increased $\operatorname{IgE}$ responses to Blo $\mathrm{t} 5$ and Blo $\mathrm{t}$ 12, two speciesspecific allergens of B. tropicalis [92]. This Ascaris-induced nonspecific boosting of the IgE responses to HDM components was also detected in a large nationwide population coexposed to A. lumbricoides and HDM, where IgE levels and frequencies of sensitization to mite allergen extracts were greater in subjects sensitized to Asc s 1. In fact, these individuals had at least twice the odds of being sensitized to HDM [93•]. Furthermore, in a cohort of asthmatic patients living in the tropics, Ascaris-sensitized patients had significantly higher IgE levels to the HDM allergens Der p 2 and Blo t 5 [94•]. All these findings support the idea that the Th2/IgE hyperresponsiveness induced by Ascaris infection (as detected by IgE antibodies to Ascaris extract or ABA-1) includes the responses not only to Ascaris antigens but also to HDM allergens. It is well known that ascariasis induces a polyclonal nonspecific stimulation of B cells; therefore, it can be hypothesized that the involved components also stimulate mite allergens-memory B cells that in the tropics are in permanent allergen-specific stimulation. It has been extensively shown that specific IgE to HDM is the most important risk factor for asthma in the tropics and some temperate countries. Therefore, any condition that increases this allergic response 
could also increase symptoms and severity of this disease. Ascaris components and host genetic background influencing this boosting effect are only beginning to be unraveled, and deserve further investigations.

\section{Conclusions}

Human ascariasis, in addition to its direct harmful effects, has other health impacts, among them boosting the Th2 allergic responses and increasing allergy symptoms. Since it is known that ascariasis induces some degree of immunomodulation, it seems that in the real life, especially in urban settings where this infection coexists with perennial mite exposure, the Th2 enhancement effects surpass the immunosuppressive influence of this helminthiasis. There is evidence suggesting that the increased allergic responses induced by ascariasis could be determined by any or a combination of the following: early age exposure and sensitization to allergens from both sources and cross reactivity between Ascaris and HDM Ascaris-induced nonspecific boosting of the IgE reactivity to mitespecific allergens

\section{Compliance with Ethics Guidelines}

Conflict of Interest Luis Caraballo, Nathalie Acevedo, and Emiro Buendia declare that they have no conflict of interest.

Human and Animal Rights and Informed Consent This article does not contain any studies with human or animal subjects performed by any of the authors.

\section{References}

Papers of particular interest, published recently, have been highlighted as:

- Of importance

1. Babu S, Nutman TB. Immunology of lymphatic filariasis. Parasite Immunol. 2014;36(8):338-46.

2. Grencis RK. Immunity to helminths: resistance, regulation, and susceptibility to gastrointestinal nematodes. Annu Rev Immunol. 2015;33:201-25.

3. Dennis RJ et al. Prevalence of asthma and other allergic conditions in Colombia 2009-2010: a cross-sectional study. BMC Pulm Med. 2012;12:17.

4. Haahtela T et al. The biodiversity hypothesis and allergic disease: world allergy organization position statement. World Allergy Organ J. 2013;6(1):3.

5. Turner KJ, Feddema L, Quinn EH. Non-specific potentiation of IgE by parasitic infections in man. Int Arch Allergy Appl Immunol. 1979;58(2):232-6.
6. Lee TD, Xie CY. IgE regulation by nematodes: the body fluid of Ascaris contains a B-cell mitogen. J Allergy Clin Immunol. 1995;95(6):1246-54.

7. Hagel I et al. Ascaris reinfection of slum children: relation with the IgE response. Clin Exp Immunol. 1993;94(1):80-3.

8. Neill DR et al. Nuocytes represent a new innate effector leukocyte that mediates type-2 immunity. Nature. 2010;464(7293):1367-70.

9. Moro $\mathrm{K}$ et al. Innate production of $\mathrm{T}(\mathrm{H}) 2$ cytokines by adipose tissue-associated c-Kit (+) Sca-1 (+) lymphoid cells. Nature. 2010;463(7280):540-4.

10. Price AE et al. Systemically dispersed innate IL-13-expressing cells in type 2 immunity. Proc Natl Acad Sci U S A. 2010;107(25):11489-94.

11. Yasuda $\mathrm{K}$ et al. Contribution of IL-33-activated type II innate lymphoid cells to pulmonary eosinophilia in intestinal nematodeinfected mice. Proc Natl Acad Sci U S A. 2012;109(9):3451-6.

12. Filbey KJ et al. Innate and adaptive type 2 immune cell responses in genetically controlled resistance to intestinal helminth infection. Immunol Cell Biol. 2014;92(5):436-48.

13. Van Dyken SJ et al. Chitin activates parallel immune modules that direct distinct inflammatory responses via innate lymphoid type 2 and gammadelta T cells. Immunity. 2014;40(3):414-24.

14. Zaiss MM et al. IL-1beta suppresses innate IL-25 and IL-33 production and maintains helminth chronicity. PLoS Pathog. 2013;9(8), e1003531.

15. Pope SM et al. IL-13 induces eosinophil recruitment into the lung by an IL-5- and eotaxin-dependent mechanism. J Allergy Clin Immunol. 2001;108(4):594-601.

16. Rothenberg ME, Hogan SP. The eosinophil. Annu Rev Immunol. 2006;24:147-74.

17. Oliphant CJ et al. MHCII-mediated dialog between group 2 innate lymphoid cells and CD4(+) T cells potentiates type 2 immunity and promotes parasitic helminth expulsion. Immunity. 2014;41(2): 283-95.

18. Liu B et al. Collaborative interactions between type 2 innate lymphoid cells and antigen-specific CD4+ Th2 cells exacerbate murine allergic airway diseases with prominent eosinophilia. J Immunol. 2015;194(8):3583-93.

19. McHedlidze $\mathrm{T}$ et al. Interleukin-33-dependent innate lymphoid cells mediate hepatic fibrosis. Immunity. 2013;39(2):357-71.

20. Hams E et al. IL-25 and type 2 innate lymphoid cells induce pulmonary fibrosis. Proc Natl Acad Sci U S A. 2014;111(1): 367-72.

21. Monticelli LA et al. Innate lymphoid cells promote lung-tissue homeostasis after infection with influenza virus. Nat Immunol. 2011;12(11):1045-54

22. Zaiss DM et al. Amphiregulin, a TH2 cytokine enhancing resistance to nematodes. Science. 2006;314(5806): 1746.

23. Turner JE et al. IL-9-mediated survival of type 2 innate lymphoid cells promotes damage control in helminth-induced lung inflammation. J Exp Med. 2013;210(13):2951-65.

24. Boyd A, Ribeiro JM, Nutman TB. Human CD117 (cKit)+ innate lymphoid cells have a discrete transcriptional profile at homeostasis and are expanded during filarial infection. PLoS One. 2014;9(9), e108649.

25. Nausch N et al. Group 2 innate lymphoid cell proportions are diminished in young helminth infected children and restored by curative anti-helminthic treatment. PLoS Negl Trop Dis. 2015;9(3), e0003627. Describes for the first time the presence of ILC2 in peripheral blood of helminth parasitized children.

26. Licona-Limon $\mathrm{P}$ et al. TH2, allergy and group 2 innate lymphoid cells. Nat Immunol. 2013;14(6):536-42.

27. Christianson, C.A., et al., Persistence of asthma requires multiple feedback circuits involving type 2 innate lymphoid cells and IL33. J Allergy Clin Immunol, 2015. Reports that ILC2 participates, 
independently of T cells, in airway hyperreactivity and remodeling in mice chronically sensitized with an allergen extract.

28. Barlow JL et al. Innate IL-13-producing nuocytes arise during allergic lung inflammation and contribute to airways hyperreactivity. J Allergy Clin Immunol. 2012;129(1):191-8 e1-4.

29. Halim TY et al. Group 2 innate lymphoid cells are critical for the initiation of adaptive Thelper 2 cell-mediated allergic lung inflammation. Immunity. 2014;40(3):425-35.

30. Bartemes KR et al. Enhanced innate type 2 immune response in peripheral blood from patients with asthma. J Allergy Clin Immunol. 2014;134(3):671-8. e4.

31. Holland CV. Predisposition to ascariasis: patterns, mechanisms and implications. Parasitology. 2009;136(12):1537-47.

32. Hlaing T, Saw T, Lwin M. Reinfection of people with Ascaris lumbricoides following single, 6-month and 12-month interval mass chemotherapy in Okpo village, rural Burma. Trans R Soc Trop Med Hyg. 1987;81(1):140-6.

33. Chan L, Bundy DA, Kan SP. Aggregation and predisposition to Ascaris lumbricoides and Trichuris trichiura at the familial level. Trans R Soc Trop Med Hyg. 1994;88(1):46-8.

34. Forrester JE et al. Predisposition of individuals and families in Mexico to heavy infection with Ascaris lumbricoides and Trichuris trichiura. Trans R Soc Trop Med Hyg. 1990;84(2): 272-6.

35. Williams-Blangero $\mathrm{S}$ et al. Host genetics and population structure effects on parasitic disease. Philos Trans R Soc Lond B Biol Sci. 2012;367(1590):887-94.

36. Cuenco KT et al. Heritable factors play a major role in determining host responses to Wuchereria bancrofti infection in an isolated south pacific island population. J Infect Dis. 2009;200(8):1271-8.

37. Williams-Blangero $\mathrm{S}$ et al. Genetic analysis of susceptibility to infection with Ascaris lumbricoides. Am J Trop Med Hyg. 1999;60(6):921-6.

38. Quinnell RJ et al. Genetic and household determinants of predisposition to human hookworm infection in a Brazilian community. J Infect Dis. 2010;202(6):954-61.

39. Gasbarre LC, Leighton EA, Davies CJ. Influence of host genetics upon antibody responses against gastrointestinal nematode infections in cattle. Vet Parasitol. 1993;46(1-4):81-91.

40. Araujo $\mathrm{RN}$ et al. Use of a candidate gene array to delineate gene expression patterns in cattle selected for resistance or susceptibility to intestinal nematodes. Vet Parasitol. 2009;162(1-2):106-15.

41. Fitzsimmons CM, Falcone FH, Dunne DW. Helminth allergens, parasite-specific $\operatorname{IgE}$, and its protective role in human immunity. Front Immunol. 2014;5:61.

42. Hagel I et al. Antibody responses and resistance against Ascaris lumbricoides infection among Venezuelan rural children: the influence of ethnicity. J Trop Pediatr. 2008;54(5):354-6.

43. Moller $\mathrm{M}$ et al. Genetic haplotypes of Th-2 immune signalling link allergy to enhanced protection to parasitic worms. Hum Mol Genet. 2007;16(15):1828-36.

44. Hopkin J. Immune and genetic aspects of asthma, allergy and parasitic worm infections: evolutionary links. Parasite Immunol. 2009;31(5):267-73.

45. Fumagalli $\mathrm{M}$ et al. The landscape of human genes involved in the immune response to parasitic worms. BMC Evol Biol. 2010;10: 264.

46. De Angelis $\mathrm{F}$ et al. Genetic response to an environmental pathogenic agent: HLA-DQ and onchocerciasis in northwestern Ecuador. Tissue Antigens. 2012;79(2):123-9.

47. Nejsum $P$ et al. High heritability for Ascaris and Trichuris infection levels in pigs. Heredity (Edinb). 2009;102(4):357-64.

48. Williams-Blangero $\mathrm{S}$ et al. Genes on chromosomes 1 and 13 have significant effects on Ascaris infection. Proc Natl Acad Sci U S A. 2002;99(8):5533-8.
49. Peisong $\mathrm{G}$ et al. An asthma-associated genetic variant of STAT6 predicts low burden of ascaris worm infestation. Genes Immun. 2004;5(1):58-62.

50. Williams-Blangero $\mathrm{S}$ et al. Localization of multiple quantitative trait loci influencing susceptibility to infection with Ascaris lumbricoides. J Infect Dis. 2008;197(1):66-71.

51. Acevedo $\mathrm{N}$ et al. Association between total immunoglobulin $\mathrm{E}$ and antibody responses to naturally acquired Ascaris lumbricoides infection and polymorphisms of immune system-related LIG4, TNFSF13B and IRS2 genes. Clin Exp Immunol. 2009;157(2): 282-90.

52. Figueiredo CA et al. Coassociations between IL10 polymorphisms, IL-10 production, helminth infection, and asthma/ wheeze in an urban tropical population in Brazil. J Allergy Clin Immunol. 2013;131(6):1683-90. An interesting genetic epidemiology work showing association among IL10 variants, asthma and helminth susceptibility in a Brazilian population.

53. $\mathrm{Zhu} \mathrm{Z}$ et al. Acidic mammalian chitinase in asthmatic $\mathrm{Th} 2$ inflammation and IL-13 pathway activation. Science. 2004;304(5677): 1678-82.

54. Bierbaum $\mathrm{S}$ et al. Polymorphisms and haplotypes of acid mammalian chitinase are associated with bronchial asthma. Am J Respir Crit Care Med. 2005;172(12):1505-9.

55. Goldman DL et al. Increased chitinase expression and fungalspecific antibodies in the bronchoalveolar lavage fluid of asthmatic children. Clin Exp Allergy. 2012;42(4):523-30.

56. Sinha $\mathrm{S}$ et al. Association of 24 bp duplication of human CHIT1 gene with asthma in a heterozygous population of north India: a case-control study. Lung. 2014;192(5):685-91.

57. Kim KW et al. Association of genetic variation in chitotriosidase with atopy in Korean children. Ann Allergy Asthma Immunol. 2013;110(6):444-9. e1.

58. Kennedy MW. Genetic control of the immune repertoire in nematode infections. Parasitol Today. 1989;5(10):316-24.

59. Kennedy MW et al. The specificity of the antibody response to internal antigens of Ascaris: heterogeneity in infected humans, and MHC (H-2) control of the repertoire in mice. Clin Exp Immunol. 1990;80(2):219-24.

60. Tomlinson LA et al. MHC restriction of the antibody repertoire to secretory antigens, and a major allergen, of the nematode parasite Ascaris. J Immunol. 1989;143(7):2349-56.

61. Christie JF et al. N-terminal amino acid sequence identity between a major allergen of Ascaris lumbricoides and Ascaris suum, and MHC-restricted IgE responses to it. Immunology. 1990;69(4): 596-602.

62. Kennedy MW, Fraser EM, Christie JF. MHC class II (I-A) region control of the IgE antibody repertoire to the ABA-1 allergen of the nematode Ascaris. Immunology. 1991;72(4):577-9.

63. Spillmann RK. Pulmonary ascariasis in tropical communities. Am J Trop Med Hyg. 1975;24(5):791-800.

64. Joubert JR, de Klerk HC, Malan C. Ascaris lumbricoides and allergic asthma: a new perspective. S Afr Med J. 1979;56(15): 599-602.

65. Joubert JR, van Schalkwyk DJ, Turner KJ. Ascaris lumbricoides and the human immunogenic response: enhanced IgE-mediated reactivity to common inhaled allergens. S Afr Med J. 1980;57(11):409-12.

66. Patterson R, Harris KE, Pruzansky JJ. Induction of IgE-mediated cutaneous, cellular, and airway reactivity in rhesus monkeys by Ascaris suum infection. J Lab Clin Med. 1983;101(6):864-72.

67. Patterson R, Harris KE. IgE-mediated rhesus monkey asthma: natural history and individual animal variation. Int Arch Allergy Immunol. 1992;97(2):154-9.

68. Tsuji $\mathrm{M}$ et al. IgE-type antibodies to Ascaris antigens in man. Int Arch Allergy Appl Immunol. 1977;55(1-6):78-81. 
69. Leonardi-Bee J, Pritchard D, Britton J. Asthma and current intestinal parasite infection: systematic review and meta-analysis. Am J Respir Crit Care Med. 2006;174(5):514-23.

70. Palmer LJ et al. Ascaris lumbricoides infection is associated with increased risk of childhood asthma and atopy in rural China. Am J Respir Crit Care Med. 2002;165(11):1489-93.

71. Takeuchi $\mathrm{H}$ et al. High titre of anti-Ascaris immunoglobulin $\mathrm{E}$ associated with bronchial asthma symptoms in 5-year-old rural Bangladeshi children. Clin Exp Allergy. 2008;38(2):276-82.

72. Hunninghake GM et al. Sensitization to Ascaris lumbricoides and severity of childhood asthma in Costa Rica. J Allergy Clin Immunol. 2007;119(3):654-61.

73. Hagel I et al. Infection by Ascaris lumbricoides and bronchial hyper reactivity: an outstanding association in Venezuelan school children from endemic areas. Acta Trop. 2007;103(3):231-41.

74. Obihara CC et al. Respiratory atopic disease, Ascarisimmunoglobulin $\mathrm{E}$ and tuberculin testing in urban south African children. Clin Exp Allergy. 2006;36(5):640-8.

75. Dold $\mathrm{S}$ et al. Ascaris-specific IgE and allergic sensitization in a cohort of school children in the former east Germany. J Allergy Clin Immunol. 1998;102(3):414-20.

76. Alcantara-Neves NM et al. The presence of serum anti-Ascaris lumbricoides IgE antibodies and of Trichuris trichiura infection are risk factors for wheezing and/or atopy in preschool-aged Brazilian children. Respir Res. 2010;11:114.

77. Pinelli E et al. Prevalence of antibodies against Ascaris suum and its association with allergic manifestations in 4-year-old children in the Netherlands: the PIAMA birth cohort study. Eur J Clin Microbiol Infect Dis. 2009;28(11):1327-34.

78. Johansson SG, Mellbin T, Vahlquist B. Immunoglobulin levels in Ethiopian preschool children with special reference to high concentrations of immunoglobulin E (IgND). Lancet. 1968;1(7552): $1118-21$.

79. Nutman TB, Hussain R, Ottesen EA. IgE production in vitro by peripheral blood mononuclear cells of patients with parasitic helminth infections. Clin Exp Immunol. 1984;58(1):174-82.

80. Kojima S, Yokogawa M, Tada T. Raised levels of serum IgE in human helminthiases. Am J Trop Med Hyg. 1972;21(6):913-8.

81. Acevedo $\mathrm{N}$ et al. Association between total immunoglobulin $\mathrm{E}$ and antibody responses to naturally acquired Ascaris lumbricoides infection and polymorphisms of immune system-related LIG4, TNFSF13B and IRS2 genes. Clin Exp Immunol. 2009;157(2): 282-90.

82. Turner KJ, Baldo BA, Anderson HR. Asthma in the highlands of New guinea total $\operatorname{IgE}$ levels and incidence of $\operatorname{IgE}$ antibodies to house dust mite and Ascaris lumbricoides. Int Arch Allergy Appl Immunol. 1975;48(6):784-99.

83. Lynch NR et al. Allergic reactivity and helminthic infection in Amerindians of the Amazon Basin. Int Arch Allergy Appl Immunol. 1983;72(4):369-72.

84. Larson D et al. Helminth infection is associated with decreased basophil responsiveness in human beings. J Allergy Clin Immunol. 2012;130(1):270-2.

85. Cooper PJ et al. Human infection with Ascaris lumbricoides is associated with a polarized cytokine response. J Infect Dis. 2000;182(4):1207-13.

86. Gelpi AP, Mustafa A. Seasonal pneumonitis with eosinophilia. A study of larval ascariasis in Saudi Arabs. Am J Trop Med Hyg. 1967;16(5):646-57.

87. Loffler W. Transient lung infiltrations with blood eosinophilia. Int Arch Allergy Immunol. 1956;8(1-2):54-9.

88. Stromberg BE. Potentiation of the reaginic (IgE) antibody response to ovalbumin in the guinea pig with a soluble metabolic product from Ascaris suum. J Immunol. 1980;125(2):833-6.
89. Marretta J, Casey FB. Effect of Ascaris suum and other adjuvants on the potentiation of the $\operatorname{IgE}$ response in guinea-pigs. Immunology. 1979;37(3):609-13.

90. Lee TD, McGibbon A. Potentiation of IgE responses to third-party antigens mediated by Ascaris suum soluble products. Int Arch Allergy Immunol. 1993;102(2):185-90.

91. Holland MJ et al. Proteins secreted by the parasitic nematode Nippostrongylus brasiliensis act as adjuvants for $\mathrm{Th} 2$ responses. Eur J Immunol. 2000;30(7):1977-87.

92. Zakzuk, J., Bornacelly, A., Mercado, D., Sánchez, J., Acevedo, N., Caraballo, L., The evolution of IgE sensitization to Ascaris allergenic components in early infancy, in Allergic diseases: from mechanisms to cure, S.J. Galli, You-Young Kim, Editor. 2014, Pacini Editore: Italy. p. 29-31.

93. Ahumada $\mathrm{V}$ et al. IgE responses to Ascaris and mite tropomyosins are risk factors for asthma. Clin Exp Allergy. 2015;45(7):1189 200. In this population based study the role of mites and Ascaris tropomyosins as risk factor for asthma is described for the first time.

94. Buendía E. The IgE response to Ascaris molecular components is associated with clinical indicators of asthma severity. WAO J. $2015 ; 8: 8$. This study shows the boosting effect of ascariasis on the human IgE responses to mite specific purified allergens.

95. Moncayo AL et al. Effects of geohelminth infection and age on the associations between allergen-specific IgE, skin test reactivity and wheeze: a case-control study. Clin Exp Allergy. 2013;43(1):6072.

96. Endara P et al. Effect of urban vs. rural residence on the association between atopy and wheeze in Latin America: findings from a case-control analysis. Clin Exp Allergy. 2015;45(2):438-47. This research in a tropical community shows the increasing effect that urbanization and helminth infections may induce on allergen sensitization.

97. Acevedo N, Erler A, Briza P, Puccio F, Ferreira F, Caraballo L. Allergenicity of Ascaris lumbricoides tropomyosin and IgE sensitization among asthmatic patients in a tropical environment. Int Arch Allergy Immunol. 2011;154:195-206.

98. Lynch NR et al. Relationship between helminthic infection and IgE response in atopic and nonatopic children in a tropical environment. J Allergy Clin Immunol. 1998;101(2 Pt 1):217-21.

99. Acevedo N, Caraballo L. IgE cross-reactivity between Ascaris lumbricoides and mite allergens: possible influences on allergic sensitization and asthma. Parasite Immunol. 2011;33(6):309-21.

100. Caraballo, L., Ascaris and Allergy, in Ascaris: the neglected parasite, C.V. Holland, Editor. 2013, Elsevier. p. 21-50.

101. Zakzuk J et al. Early life IgE responses in children living in the tropics: a prospective analysis. Pediatr Allergy Immunol. 2013;24(8):788-97.

102. Acevedo $\mathrm{N}$ et al. IgE cross-reactivity between Ascaris and domestic mite allergens: the role of tropomyosin and the nematode polyprotein ABA-1. Allergy. 2009;64(11):1635-43.

103. Acevedo $\mathrm{N}$ et al. Allergenicity of Ascaris lumbricoides tropomyosin and IgE sensitization among asthmatic patients in a tropical environment. Int Arch Allergy Immunol. 2011;154(3):195-206.

104. Acevedo $\mathrm{N}$ et al. Proteomic and immunochemical characterization of glutathione transferase as a new allergen of the nematode Ascaris lumbricoides. PLoS One. 2013;8(11), e78353.

105. Mueller, G.A., et al., Analysis of glutathione S-transferase allergen cross-reactivity in a North American population: Relevance for molecular diagnosis. J Allergy Clin Immunol, 2015

106. Acevedo $\mathrm{N}$ et al. Particular characteristics of allergic symptoms in tropical environments: follow up to 24 months in the FRAAT birth cohort study. BMC Pulm Med. 2012;12(1):13. 